\title{
Griffithsin inhibits porcine reproductive and respiratory syndrome virus infection in vitro
}

\author{
Lan $\mathrm{Li}^{1} \cdot$ Xiaoning Tian $^{2} \cdot$ Jin Chen ${ }^{1} \cdot$ Pengcheng $\mathrm{Li}^{1}$ · Qisheng Zheng ${ }^{1} \cdot \mathrm{Jibo} \mathrm{Hou}^{1,3}$
}

Received: 18 May 2018 / Accepted: 1 August 2018 / Published online: 15 September 2018

(c) Springer-Verlag GmbH Austria, part of Springer Nature 2018

\begin{abstract}
Porcine reproductive and respiratory syndrome virus (PRRSV) is a pathogen that severely disrupts swine production. Despite sustained efforts, the disease is still endemic, with high mortality and morbidity. New antiviral strategies to control PRRSV are needed. Griffithsin, a red algal lectin, has potent antiviral effect on several human enveloped viruses, but this effect has not been demonstrated on PRRSV. Here, we first tested the in vitro antiviral activity of Griffithsin against PRRSV. Griffithsin exerted strong saccharide-dependent antiviral activity against PRRSV, probably through interactions with glycans on the surface of PRRSV that interfered with virus entry. Furthermore we revealed that Griffithsin's action on PRRSV involved blocking viral adsorption, and it had no effect on viral penetration. Besides Our findings also suggested that Griffithsin may interfere with cell-to-cell spread to prevent virus transmission. The remarkable potency profile of Griffithsin supports its potential value as an antiviral agent against PRRSV.
\end{abstract}

\section{Introduction}

Infection by porcine reproductive and respiratory syndrome virus (PRRSV) causes devastating disease in swine, resulting in significant economic losses estimated at \$644 million per year in the United States [1]. PRRSV is an enveloped, single-stranded positive-sense RNA virus. Its $15.4 \mathrm{~kb}$ genome contains at least 10 open reading frames [2], four of which encode envelope glycoproteins designated GP2a, GP3, GP4 and GP5. GP5 has been proposed as the major mediator of PRRSV entry into target cells.

Handling Editor: Zhenhai Chen.

Lan Li, Xiaoning Tian equal contribution.

Qisheng Zheng

njcvc1302@163.com

$\triangle$ Jibo Hou

houjiboccvv@163.com

Lan Li

lanli99@foxmail.com

Xiaoning Tian

15733223151@163.com

Jin Chen

chenjin_abc@163.com

Pengcheng Li

lipengcheng305@163.com
PRRSV infection can cause respiratory distress, reproductive dysfunction and weight loss. Moreover, PRRSV infection confers susceptibility to secondary infection by other viruses or bacteria. Vaccination is the most common prophylactic measure used to protect pigs against PRRSV infection. Currently, modified live virus (MLV) PRRSV vaccines are considered most effective although probably because of PRRSV genetic variation, MLV vaccines have failed to confer complete protection against drift variants [3, 4]. Thus, there is a need for novel antiviral drugs that could be used for prevention and control of PRRSV infection.

Griffithsin, derived from Griffithsia spp. marine red algae., is a small lectin consisting of 121 amino acids [5]. Griffithsin is a domain-swapped dimer and each subunit has

1 National Research, Center of Engineering and Technology for Veterinary Biologicals, Jiangsu Academy of Agricultural Sciences, Nanjing 210014, Jiangsu, People's Republic of China

2 College of Veterinary Medicine, Nanjing Agricultural University, Nanjing 210095, Jiangsu, People's Republic of China

3 Jiangsu Co-innovation Center for Prevention and Control of Important Animal Infectious Diseases and Zoonoses, Yangzhou 225009, Jiangsu, People's Republic of China 
three nearly equivalent glycan-binding sites [6]. Griffithsin binds glycan moieties associated with the glycoproteins of several enveloped viruses [7], resulting in inhibition of infectivity. Griffithsin has been shown to exhibit significant antiviral activity against human enveloped viruses including HIV [5, 8], Middle East respiratory syndrome coronavirus (MERS-CoV) [9], severe acute respiratory syndrome corona virus (SARS-CoV) [6, 10], hepatitis $\mathrm{C}$ virus (HCV) $[11,12]$, herpes simplex virus 2 (HSV-2) [13] and Japanese encephalitis virus (JEV) [14, 15]. Moreover, Griffithsin shows excellent thermostability [16], remaining stable up to $80^{\circ} \mathrm{C}$, and is resistant to organic solvents [5] and protease degradation [17]. The cytotoxicity of Griffithsin has been studied extensively $[18,19]$, showing that it possesses a superior safety profile: no cytotoxicity was observed against a variety of cell types, nor any major effects on peripheral blood mononuclear cell activation or cytokine and chemokine production. Thus, Griffithsin is an attractive candidate for development as an antiviral therapeutic.

In this study, we assessed the antiviral activity of Griffithsin against PRRSV in Marc-145 cells. Our results revealed that Griffithsin could effectively reduce PRRSV infection by blocking virus adsorption, indicating that Griffithsin may be a promising antiviral agent for treatment of PRRSV.

\section{Materials and methods}

\section{Cells and viruses}

Marc-145 cells were grown in Dulbecco's Modified Eagle's Medium (DMEM) (Gibco, USA) supplemented with $10 \%$ fetal bovine serum at $37^{\circ} \mathrm{C}$ under an atmosphere of $5 \% \mathrm{CO}_{2}$. Highly pathogenic PRRSV strain NJ-a (type 2) [20] was isolated, identified and stored in our laboratory at National Research Center of Engineering and Technology for Veterinary Biologicals, Jiangsu Academy of Agricultural Science. $\mathrm{NJ}$-a strain was propagated in Marc-145 cells and viral stocks were titered to determine their $\mathrm{TCID}_{50}$.

\section{Protein expression and purification}

A codon-optimized gene encoding Griffithsin (GenBank accession no. FJ594069) C-terminally tagged with $\mathrm{His}_{6}$ was synthesized and cloned into the pUC57 vector using GenScript (Nanjing, China). Then recombinant plasmid pUC57Griffithsin was introduced into the NdeI-XhoI digested pET$32 \mathrm{a}$ vector to obtain the recombinant expression plasmid pET-32a-Griffithsin. Competent E. coli BL21 (DE3) cells were transformed with the recombinant expression plasmid. Gene expression was carried out as described in the pET system manual (Novagen, USA). Briefly, a single colony from the recombinant $E$. coli strains was grown overnight at $37^{\circ} \mathrm{C}$ in LB broth containing $100 \mu \mathrm{g} / \mathrm{mL}$ ampicillin and $20 \mu \mathrm{g} / \mathrm{mL}$ chloramphenicol. Then The overnight cultures were diluted in $400 \mathrm{~mL}$ of fresh LB broth at $37^{\circ} \mathrm{C}$ until the optical density at $600 \mathrm{~nm}$ reached 1.0. Protein expression was induced with $1 \mathrm{mM}$ isopropyl-beta-D-thiogalactopyranoside (IPTG). After further incubation for $24 \mathrm{~h}$ at $15^{\circ} \mathrm{C}$, the culture was harvested and resuspended in PBS. Then the cells were disrupted by high-pressure homogenization for two cycles. Finally, the cell lysates were centrifuged at $12000 \times \mathrm{g}$ for 20 $\min$ at $4{ }^{\circ} \mathrm{C}$ and the resulting crude extract containing Griffithsin was applied to a $5 \mathrm{~mL} \mathrm{Ni}^{2+}$-Sepharose HisTrap $\mathrm{HP}^{\mathrm{TM}}$ affinity column (GE Healthcare, Sweden) and eluted with $300 \mathrm{mM}$ imidazole. The protein was dialyzed and further purified by endotoxin removal and filter sterilization, then quantified using a BCA Protein Assay Reagent Kit (Pierce, USA). SDS-PAGE was used to analyze protein production.

\section{Circular dichroism (CD) analysis of secondary structure}

$\mathrm{CD}$ measurements were recorded at $25^{\circ} \mathrm{C}$ using a JASCO J-1500 spectropolarimeter. Purified Griffithsin was diluted to $200 \mu \mathrm{g} / \mathrm{mL}$ in $0.01 \mathrm{mM}$ phosphate buffer, $\mathrm{pH}$ 7.2. Spectra were measured from $250 \mathrm{~nm}$ to $197 \mathrm{~nm}$ in a quartz cell with $0.1 \mathrm{~cm}$ path length, with a scanning speed of $100 \mathrm{~nm} / \mathrm{min}$ and a data pitch of $1.0 \mathrm{~nm}$. Phosphate buffer was used as a blank. The relative proportions of $\alpha$-helix, $\beta$-sheet, $\beta$-turn and disordered conformation were analyzed using the Spectra Manager ${ }^{\mathrm{TM}}$ software platform.

\section{Detection of Griffithsin by enzyme-linked immunosorbent assay (ELISA)}

Binding of Griffithsin to glycans was evaluated by ELISA as previously described. [21, 22]. Briefly, flat-bottom 96-well microtiter plates (Nunc, Maxiscorp, MD, USA) were coated with $10 \mu \mathrm{g}$ of ovalbumin (OVA). The plates were then washed with PBS and blocked by $3 \%(\mathrm{w} / \mathrm{v})$ bovine serum albumin (BSA). Either Griffithsin alone or Griffithsin preincubated with $100 \mathrm{mM} \mathrm{D-(+)-glucose} \mathrm{or} \mathrm{D-(+)-mannose}$ was added to the wells. The wells only contained the BSA was as a blank. An anti-His ${ }_{6}$ antibody (Boster, Wuhan, China) and horseradish peroxidase (HRP)-conjugated secondary antibody (Boster, Wuhan, China) were used to detect Griffithsin binding. After developing with 3,3',5,5'-tetramethylbenzidine (TMB) substrate, the reaction was stopped with $2 \mathrm{M} \mathrm{H}_{2} \mathrm{SO}_{4}$ and plates were read using a microplate spectrophotometer (BioTec) at a wavelength of $450 \mathrm{~nm}$.

\section{Cell viability assay}

To evaluate the cytotoxicity of Griffithsin, Marc-145 cells in 96-well plates were treated for $48 \mathrm{~h}$ with different 
concentrations of Griffithsin ranging from 0 to $5 \mu \mathrm{g} / \mathrm{mL}$, and viability was measured using MTT assay. MTT was added to wells and incubated for $4 \mathrm{~h}$. After removing the supernatant, dimethyl sulfoxide (DMSO) was added to each well for 10 min to dissolve the crystals and the absorbance at $490 \mathrm{~nm}$ was measured.

\section{Inhibition of PRRSV by Griffithsin}

Increasing concentrations of Griffithsin were pre-incubated with PRRSV at room temperature for $30 \mathrm{~min}$, and then the virions were used to infect cells at a multiplicity of infection (MOI) of 5 and 10 for $30 \mathrm{~min}$ at room temperature. For competition assays, Griffithsin was pre-incubated with 100 mM D-(+)-mannose before incubation with PRRSV. Subsequently, the mixture was transferred to Marc-145 cells in 96-well plates. Uninfected cells served as a negative control, and cells infected with PRRSV served as a positive control. The cells were cultured at $37^{\circ} \mathrm{C}$ for $1 \mathrm{~h}$ and washed with PBS to remove unbound virus. Fresh medium was added and the cells were cultured for $24 \mathrm{~h}$.

The presence of PRRSV was further assessed by indirect immunofluorescence assay. Cells were fixed with precooled methanol for $10 \mathrm{~min}$ at room temperature, blocked with PBS containing 3\% (w/v) bovine serum albumin (BSA) for $3 \mathrm{~h}$ at $37^{\circ} \mathrm{C}$, and then incubated with anti-PRRSV GP5 protein monoclonal antibody (TONGDIAN, Hangzhou, China) diluted $1: 1000$ in $1 \% \mathrm{BSA} / \mathrm{PBS}$ for $1 \mathrm{~h}$ at $37^{\circ} \mathrm{C}$. After washing three times with PBS, the cells were incubated with FITC-conjugated goat anti-mouse IgG antibody (Boster,Wuhan, China) diluted 1:50 for $1 \mathrm{~h}$ at $37^{\circ} \mathrm{C}$ in the dark. After washing, the cells were stained with DAPI for 10 min at room temperature, washed again, and samples were observed using a Cytation ${ }^{\mathrm{TM}} 5$ Cell Imaging Multi-Mode Reader (BioTek).

For quantitation of infected cells, three fields were randomly collected and processed for quantification using automatic cell counting software (Imaris 7.2.3). The results of quantitation were expressed as the percentage of infected cells.

\section{Real-time quantitative PCR (RT-qPCR)}

Total RNA was extracted from samples using a MiniBEST Universal RNA Extraction Kit (TaKaRa, Osaka, Japan) and converted to cDNA using PrimeScript ${ }^{\mathrm{TM}}$ Reverse Transcriptase. RT-qPCR was performed with a LightCycler 480 II System (Roche, Basel, Switzerland) using the EvaGreen $2 \times$ qPCR MasterMix-No Dye kit (abm, Canada) according to the manufacturer's recommendations. The forward primer (FP) and reverse primer (RP) for PRRSV and GAPDH were as follows: PRRSV-FP: 5'-TCTGGACACTAAGGGCAG ACTC-3', PRRSV-RP: 5'-GGAACCATCAAGCACAAC
TCTC-3', GAPDH-FP: 5'-CCTTCCGTGTCCCT ACTGCC AAC-3', GAPDH -RP: 5'-GACGCCTGCTTCACCACC TTCT- $3^{\prime}$. Data were analyzed using the $2^{-\Delta \Delta \mathrm{Ct}}$ method. Each assay was performed in triplicate.

\section{Western blot analysis}

Cells were lysed in cell lysis buffer (20 mM Tris, $\mathrm{pH} 7.5$, $150 \mathrm{mM} \mathrm{NaCl}, 1 \%$ Triton X-100, $0.1 \mathrm{mM}$ phenylmethylsulfonyl fluoride). Protein content was measured using the BCA Protein Assay Reagent Kit (Pierce, Rockford, IL, USA) and $20 \mu \mathrm{g}$ total protein was loaded on a $12 \%$ sodium dodecyl sulfate-polyacrylamide gel electrophoresis (SDS-PAGE) gel, transferred to a polyvinyl difluoride (PVDF) membrane and blocked with TBS containing 5\% skim milk and $0.1 \%$ Tween- 20 at $37^{\circ} \mathrm{C}$ for $2 \mathrm{~h}$. Membranes were incubated overnight with gentle shaking at $4^{\circ} \mathrm{C}$ with mouse anti-PRRSV GP5 antibody (1:500, TONGDIAN, Hangzhou, China) or mouse anti- $\beta$-actin antibody (1:200, Boster, Wuhan, China). After washing, membranes were incubated with HRPconjugated goat anti-mouse IgG (1:5,000, Boster, Wuhan, China) for $1 \mathrm{~h}$ at $37^{\circ} \mathrm{C}$. Antibodies were visualized using an enhanced chemiluminescence reagent and images were recorded using a ImageQuant LAS 4000 instrument (GE Healthcare, Sweden).

\section{Effect of Griffithsin on PRRSV entry stages}

Subconfluent monolayers of Marc- 145 cells in 6-well plates were washed with cold PBS followed by DMED and then were pre-chilled at $4^{\circ} \mathrm{C}$ for $30 \mathrm{~min}$. In adsorption assay, cells were incubated with PRRSV $(\mathrm{MOI}=5)$ in the presence or absence of Griffithsin at $4^{\circ} \mathrm{C}$ for $1 \mathrm{~h}$. Griffithsin pre-incubated with $100 \mathrm{mM} \mathrm{D-(+)-mannose} \mathrm{was} \mathrm{served} \mathrm{as} \mathrm{a} \mathrm{con-}$ trol. After washing with cold PBS to remove unbound virus, cells were harvested for viral genomic RNA detection using RT-qPCR as described above; In penetration assay, cells were infected with PRRSV at an MOI of 5 and incubated at $4^{\circ} \mathrm{C}$ for $1 \mathrm{~h}$. After washing with cold PBS, some cells were treated with Griffithsin and shifted to $37^{\circ} \mathrm{C}$ for $1 \mathrm{~h}$ allowing for viral penetration. After removing Griffithsin, cells were also harvested for RT-qPCR detection as above description. described above

\section{Griffithsin agglutination assay}

Red blood cells collected from avian, swine, goat, guinea pig and mice were washed and resuspended in PBS at a final concentration of $1 \%(\mathrm{v} / \mathrm{v})$. Twenty-five $\mu \mathrm{L}$ of Griffithsin (serially diluted two-fold) were mixed with an equal volume of erythrocytes in a 96-well v-bottom plate. The plate was incubated at room temperature for $30 \mathrm{~min}$ and results 
Fig. 1 Identification of recombinant plasmid pUC57-Griffithsin and SDS-PAGE analyses of Griffithsin. (A) Recombinant plasmid pUC57-Griffithsin was digested by NdeI-XhoI and verified in $1 \%$ Agarose Gel. (B) Recombinant Griffithsin was purified by $\mathrm{Ni}^{2+}$ - Sepharose HisTrap $\mathrm{HP}^{\mathrm{TM}}$ affinity column by the analysis of Crude extract (Crude), Flow-through after loading crude extract on affinity column (FT), Fraction obtained by washing with $50 \mathrm{mM}$ imidazole (Wash) and Fractions eluted with $300 \mathrm{mM}$ imidazole.
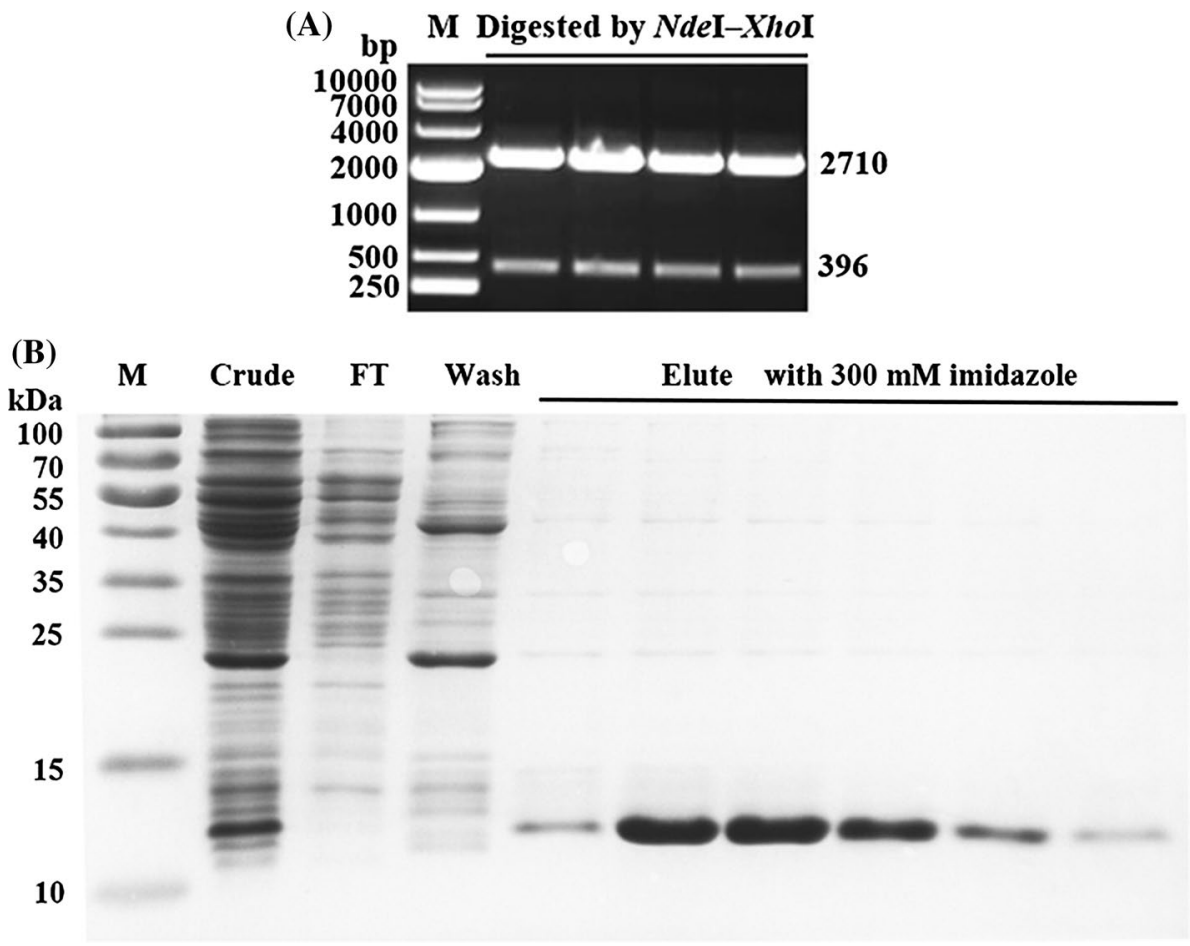

were recorded using a Gel Image System (Tanon, Shanghai, China).

\section{Data analysis}

Data were presented as the mean \pm standard deviation of three independent experiments. Differences between group means were analyzed using the Student's $t$-test with GraphPad Prism 6 software. Statistical significance was assumed when $P<0.05$.

\section{Results}

\section{Secondary structure analysis using CD spectroscopy}

The recombinant plasmid pUC57-Griffithsin was verified by restriction enzyme digestion (Fig. 1A) and recombinant Griffithsin was successfully expressed in E. coli and readily purified to homogeneity (Fig. 1B). To assess whether Griffithsin was well folded, we first studied its secondary structure using CD spectroscopy. The CD spectrum of Griffithsin displayed a maximum at $220.5 \mathrm{~nm}$ and a minimum at $199.5 \mathrm{~nm}$ (Fig. 2) which was consistent with a structure composed mainly of $\beta$-sheets. As shown in Table 1 , Griffithsin secondary structure consisted mostly of $\beta$-sheets (51.1\%) with roughly equal proportions of $a$-helices and turns.

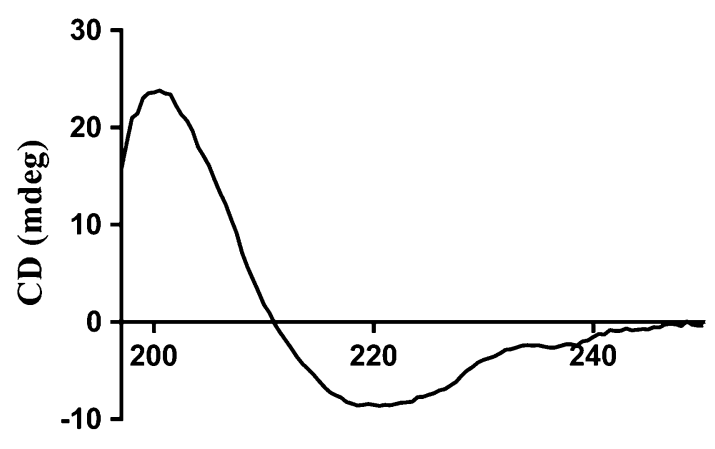

Wavelength (nm)

Fig. $2 \mathrm{CD}$ spectrum of recombinant Griffithsin in $0.01 \mathrm{mM}$ phosphate buffer, $\mathrm{pH} 7.2$

Table 1 Secondary structure composition of recombinant griffiths in determined from its $\mathrm{CD}$ spectrum in the far-ultraviolet region at $25^{\circ} \mathrm{C}$

\begin{tabular}{lllll}
\hline Sample & $a$-helix (\%) & $\beta$-sheet (\%) & $\beta$-turn (\%) & $\begin{array}{l}\text { Random coil } \\
(\%)\end{array}$ \\
\hline $\begin{array}{l}\text { Recombinant } \\
\text { griffithsin }\end{array}$ & 23.1 & 51.1 & 21.6 & 4.3 \\
\hline
\end{tabular}

\section{Assessment of Griffithsin binding to OVA}

The ability of Griffithsin to bind glycans was assessed by ELISA against immobilized OVA. OVA contains a single $\mathrm{N}$-linked glycosylation site, in which bind to high-mannose and hybrid $\mathrm{N}$-linked glycans have been characterized. 
ELISA measurements revealed that Griffithsin interacted with OVA in a dose-dependent manner. OVA binding by Griffithsin was efficiently inhibited by $100 \mathrm{mM}$ mannose and slightly less efficiently inhibited by $100 \mathrm{mM}$ glucose, indicating that Griffithsin bound mannose with higher affinity compared with glucose (Fig. 3).

\section{Griffithsin inhibits PRRSV infection in vitro}

Immunofluorescence microscopy revealed that Griffithsin potently inhibited PRRSV infection of Marc-145 cells. As shown in Fig. 4.A, Griffithsin significantly decreased PRRSV infectivity in a dose-dependent manner, and this inhibition was substantially diminished in the presence of $100 \mathrm{mM}$ mannose. Furthermore, the infection rate of $95.1 \%$ in the presence of $0 \mu \mathrm{g} / \mathrm{mL}$ Griffithsin, was reduced to $25.3 \%$ in the presence of $4 \mu \mathrm{g} / \mathrm{mL}$ Griffithsin when Marc-145 cells were infected with PRRSV at a MOI of 10 (Fig. 4.B). More significant reduction was observed when the cells were infected with 5 MOI PRRSV, where infection rate was reduced to $4.4 \%$ from $81.3 \%$ in the presence of $4 \mu \mathrm{g} / \mathrm{mL}$ Griffithsin (Fig. 4.B).

To understand whether these experimental results might instead be explained by a cytotoxic effect of Griffithsin, we assessed whether Griffithsin affected the proliferative activity of Marc-145 cells. As shown in Fig. 5, cells cultured in medium containing Griffithsin at the same concentrations as used in this study retained $100 \%$ viability compared with control cells.

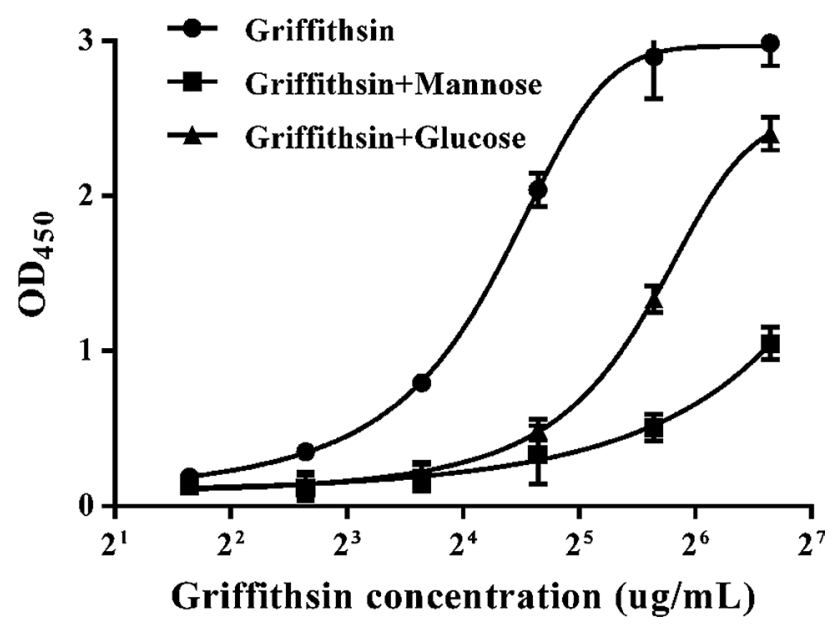

Fig. 3 ELISA binding of Griffithsin (circles), Griffithsin pre-incubated with mannose (squares) or Griffithsin pre-incubated with glucose (triangles) to OVA.

\section{Griffithsin prevents the adsorption stage of PRRSV infection}

To elucidate the mechanism of the antiviral effects of Griffithsin, a virus entry assay was performed. The data indicated that Griffithsin greatly repressed virus adsorption to cells, with no effects on virus penetration.

Marc-145 cells were incubated with PRRSV and Griffithsin at $4^{\circ} \mathrm{C}$ in the presence or absence of mannose to allow virus adsorption but not penetration. As shown in Fig. 6, $4 \mu \mathrm{g} / \mathrm{mL}$ Griffithsin greatly repressed PRRSV adsorption but had no effect on virions treated with Griffithsin in the presence of mannose $(P=0.03)$. No significant impact on PRRSV infectivity was observed when Griffithsin was added during viral penetration $(P>0.05)$.

\section{Effects of Griffithsin on viral load measured using RT-qPCR and western blot}

RT-qPCR was performed to investigate the effect of Griffithsin on intracellular viral load. Marc-145 cells were incubated with PRRSV at a MOI of 5 for $24 \mathrm{~h}$, and then growth media was then replaced with fresh medium containing $4 \mu \mathrm{g} / \mathrm{mL}$ Griffithsin. Abundance of PRRSV GP5 RNA in Marc-145 cells was analyzed at different times post-Griffithsin treatment. As shown in Fig. 7.A, compared with the corresponding untreated control group, PRRSV RNA levels in the Griffithsin-treated group showed the highest decreases at $12 \mathrm{~h}(P<0.001), 24 \mathrm{~h}(P<0.001)$, and $36 \mathrm{~h}(P<0.001)$. However, no significant differences in RNA abundance were observed at $6 \mathrm{~h}$ post-Griffithsin addition $(P>0.05)$. We also measured levels of PRRSV GP5 protein in Marc-145 cells using western blot after 36 h Griffithsin treatment. The results showed that expression of PRRSV GP5 was significantly reduced following Griffithsin treatment in a dose-dependent manner (Fig. 7.B).

\section{Agglutination of Griffithsin}

Since Griffithsin belongs to a group of lectins that potentially induce hemagglutination, so we determined whether Griffithsin had any hemagglutination activity. We tested blood cells derived from several species including avian, swine, goat, guinea pig and mice, and the results are shown in Fig. 8. The red cells of most species' red blood cells were not agglutinated by Griffithsin. with the exception of guinea pig red blood cells, which were agglutinated in the presence of Griffithsin when used at a concentrations higher than $12.5 \mu \mathrm{g} / \mathrm{mL}$. 
(A)

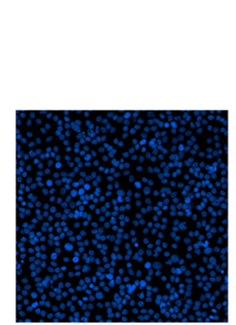

N.I.
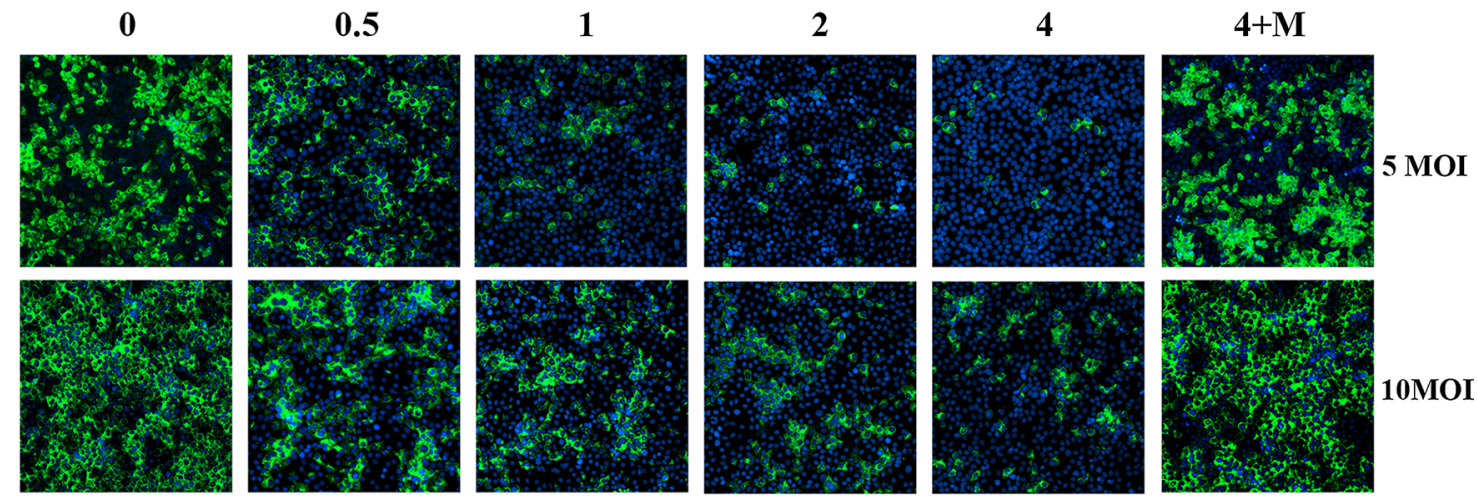

PRRSV infected

(B)

5 MOI

$10 \mathrm{MOI}$

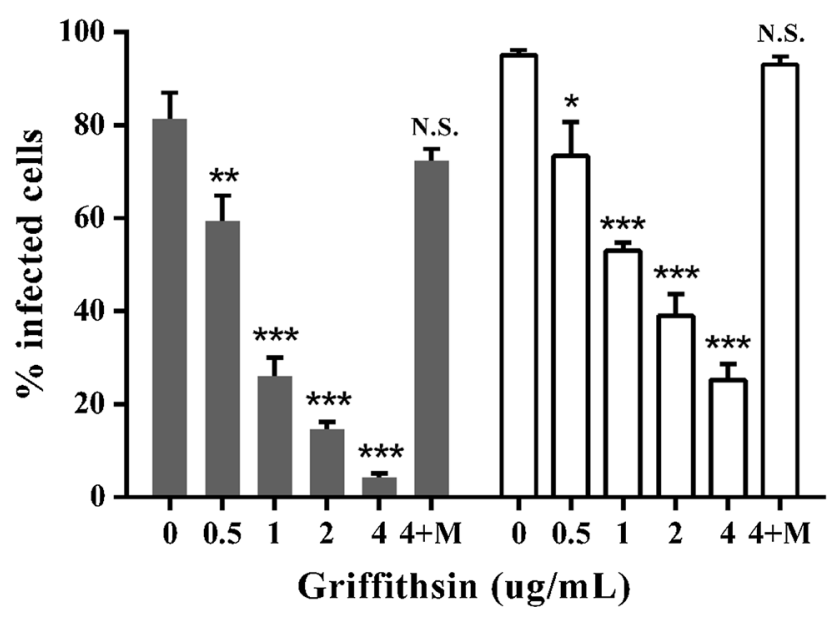

Fig. 4 Griffithsin inhibits PRRSV infection of Marc-145 cells. (A) Indirect immunofluorescence assay of PRRSV-infected Marc-145 cells in the presence of Griffithsin. (B) Quantification of PRRSV infected cells with the treatment of Griffithsin. The results are expressed as percent-infected cells calculated from the number of

\section{Discussion}

Griffithsin is currently considered the most potent anti-HIV agent for blocking virus entry by interacting with with the Env glycoprotein on the surface of HIV, exhibiting antiviral activity at concentrations in the nanomolar to picomolar range [8]. However, the antiviral activity of Griffithsin against PRRSV has not been investigated . PRRSV, like HIV, is an enveloped virus. and its major envelope glycoprotein, GP5, is heavily glycosylated [23, 24]. We analyzed therefore the potential ability of Griffithsin to inhibit infection by PRRSV, with the hope of developing a novel antiviral strategy for PRRSV therapy.

To further study its antiviral activity against enveloped viruses of veterinary importance, biologically active recombinant Griffithsin was produced in E. coli with high infected cells (FITC stain) / total number of cells (DAPI nuclei stain) $\times 100 \%$. Each value represents the mean of three independent experiments and its standard derivation. $* P<0.05, * * P<0.01$ and $* * * P$ $<0.001$ compared to the $0 \mu \mathrm{g} / \mathrm{mL}$ control group.

expression yields. Our data indicated that the major secondary structure elements of Griffithsin were $\beta$-sheets, consistent with previous reports $[6,25]$, indicating that its overall fold was probably similar to that of natural Griffithsin. Additional ELISA experiments demonstrated that the glycan-binding ability of Griffithsin, which was critical for its antiviral activity and further evaluated the anti-PRRSV activity of Griffithsin.

Our results showed that Griffithsin possessed potent antiviral activity against PRRSV in Marc-145 cells. Previous studies have been reported that certain lectins like porcine SP-A are able to inhibit inhibited PRRSV infection [26-30]. . Interestingly, Griffithsin was found to reduce PRRSV infectivity of Marc-145 cells at a 7.5-fold lower concentrations and at a 500-fold higher MOI compared with porcine SP-A [20]. Porcine ficolin $(10 \mu \mathrm{g} / \mathrm{mL})$ which 


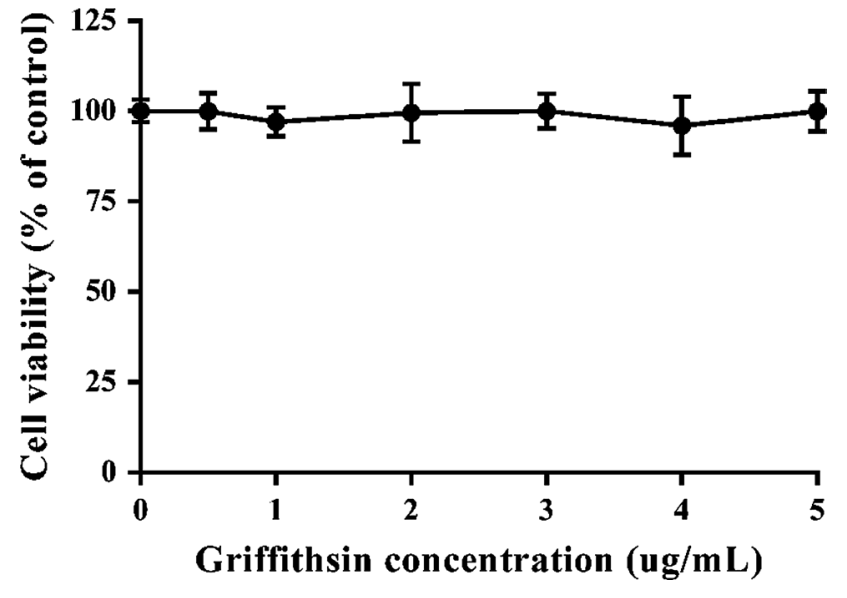

Fig. 5 Cytotoxicity of Griffithsin in Marc-145 cells was measured using the MTT assay. Cells were incubated with different concentrations of Griffithsin for $48 \mathrm{~h}$, and then the cell viability assay was performed.

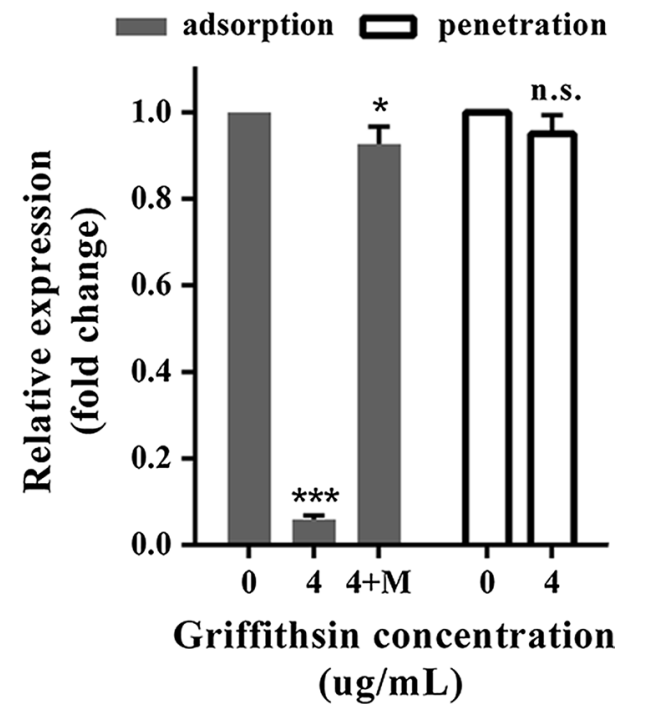

Fig. 6 Effect of Griffithsin on PRRSV entry stages. In control group, cells were infected with PRRSV without Griffithsin treatment at any stage. Data are presented as means \pm standard deviations of three independent experiments. $* P<0.05$; $* * P<0.01$; *** $P<0.001$ compared to the control group.

is also a lectin a lectin has also been shown to inhibit PRRSV infection [31]. However, our previous work demonstrated that solubility and low expression represented were the main obstacles to large-scale cost-effective production of biologically active ficolin. Finally, Although many other antivirals against PRRSV have been described in the literature, none have been able to effectively treat or prevent PRRSV infection in vivo for whatever reason .and Griffithsin may thus represent a candidate agent for preventing or treating PRRSV infection.

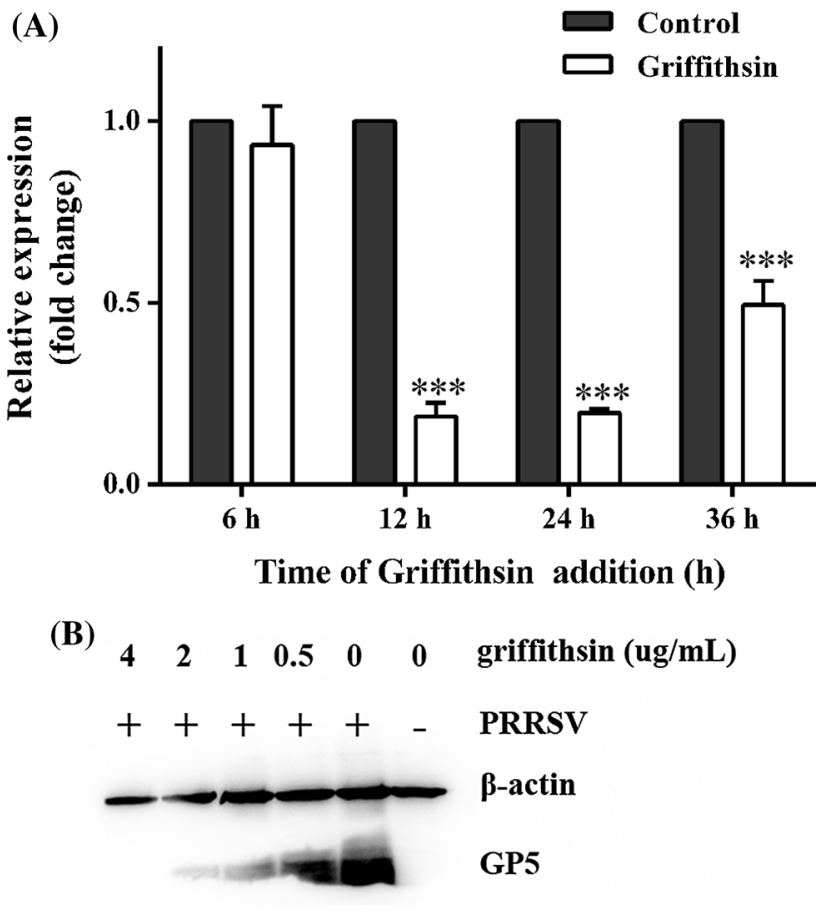

Fig. 7 Influence of Griffithsin on total PRRSV RNA and protein levels in Marc-45 cells. (A) Level of PRRSV RNA after treatment was determined by RT-qPCR at different time points post-infection with Griffithsin-treated virions. Relative expression (fold change) in comparison with a control group not treated with Griffithsin (denoted as 1 ) is illustrated. Data are presented as means \pm standard deviations of three independent experiments. $* P<0.05$; $* * P<0.01$; $* * * P<$ 0.001 compared to the control group. (B) The PRRSV GP5 protein and $\beta$-actin were detected by western blot. $\beta$-actin was used as the internal control.

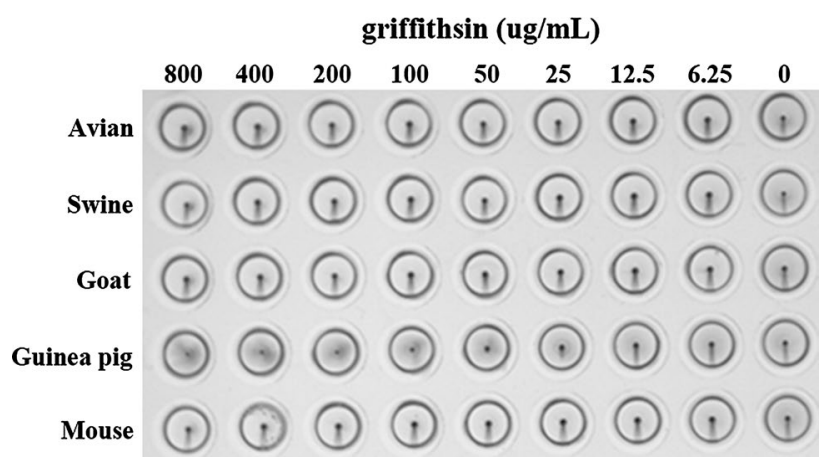

Fig. 8 Griffithsin hemagglutination activity. Avian, swine, goat, guinea pig and mouse erythrocytes were used to assess the hemagglutination activity of Griffithsin.

Another key finding of our study was that Griffithsin inhibited infection by PRRSV using a higher dose than for HIV strains, but at lower than that required those for SARS-CoV strains [7]. Since the HIV Env glycoprotein is heavily glycosylated containing up to $50 \%$ carbohydrate 
by weight $[8,32]$, this may explain Griffithsin's potent anti-HV activity. The antiviral properties of Griffithsin against enveloped viruses is thus likely to be related to the glycosylation of viral proteins, a hypothesis that should be further investigated by further studies.

Most interestingly, our results clearly showed that Griffithsin was able to block virus adsorption but had only modest effects on virus penetration, which is consistent with most previous reports. Millet and colleagues performed detailed studies to define the viral life cycle stage at which Griffithsin acted and found that Griffithsin inhibited MERS-CoV by acting on the adsorption stage [9]. By contrast, Griffithsin exhibited its antiviral activity against HSV-2 by preventing cell-to-cell spread, but had little effect on HSV-2 entry into target cells [33]. The reason for this difference may be related to the virus itself and its entry receptors. Further studies are needed to clarify the anti-PRRSV activity of Griffithsin in porcine alveolar macrophages, the main targets of PRRSV infection in vivo.

Our data clearly showed that Griffithsin displayed its antiviral activity in a saccharide-dependent manner. Taking our own findings and the results of previous studies together, we inferred that the binding of Griffithsin to PRRSV glycoproteins prevented PRRSV attachment to target cells, possibly due to steric hindrance or loss of PRRSV receptor-binding ability. Previous studies revealed that Griffithsin reduced HIV, HCV, SARS-CoV, MERS$\mathrm{CoV}$, and JEV infectivity through binding to viral glycoproteins, thereby blocking viral entry. It was also confirmed that Griffithsin could bind to glycoprotein of HSV-2 and inhibited viral transmission by blocking cell-to-cell spread. Interestingly, Griffithsin also has antiviral activity against HPV, a non-enveloped virus, by binding to the secondary receptor $\alpha 6$ integrin and decreasing its availability on the cell surface [7]. Due to the uncertain nature of the interactions between Griffithsin, PRRSV and host cells, its mode of action should be clarified in future studies.

Our study also showed that Griffithsin greatly reduced total viral RNA $12 \mathrm{~h}, 24 \mathrm{~h}$ and $36 \mathrm{~h}$ post-infection, but had no effect at $6 \mathrm{~h}$ post-infection, after the initial rounds of viral replication. This finding suggested that Griffithsin may neutralize progeny virions and/or interfere with cellto-cell spread, a possibility which needs to be studied by future work.

In conclusion, our study provides the first evidence of the antiviral activity of Griffithsin against PRRSV. Our results revealed that Griffithsin exerted a potent inhibitory effect on highly pathogenic PRRSV by interfering with viral entry and/or cell-to-cell spread. Thus, Griffithsin may seems to be a candidate agent for preventing PRRSV infection and further studies in live animals are necessary to confirm its value for inhibiting PRRSV infection in vivo.
Acknowledgements This study was supported by grants from the Special Fund for Agro-scientific Research in the Public Interest (No. 201303046). The erythrocytes were kindly provided by Yiwei Wang.

\section{Compliance with ethical standards}

Conflict of interest The authors declare that they have no conflicts of interest.

Ethical approval This article does not contain any studies with human participants or animals performed by any of the authors.

\section{References}

1. Kristensen C, Kvisgaard L, Pawlowski M, Holmgaard Carlsen S, Hjulsager C, Heegaard P, Bøtner A, Stadejek T, Haugegaard S, Larsen L (2017) Efficacy and safety of simultaneous vaccination with two modified live virus vaccines against porcine reproductive and respiratory syndrome virus types 1 and 2 in pigs. Vaccine 36(2):227-236

2. Chand RJ, Trible BR, Rowland RR (2012) Pathogenesis of porcine reproductive and respiratory syndrome virus. Curr Opin Virol 2:256-263

3. Renukaradhya GJ, Meng XJ, Calvert JG, Roof M, Lager KM (2015) Inactivated and subunit vaccines against porcine reproductive and respiratory syndrome: current status and future direction. Vaccine 33:3065-3072

4. Renukaradhya GJ, Meng XJ, Calvert JG, Roof M, Lager KM (2015) Live porcine reproductive and respiratory syndrome virus vaccines: current status and future direction. Vaccine 33:3065-3072

5. Mori T, O'Keefe BR, Bringans S, Gardella R, Berg S, Cochran P, Turpin JA Jr, Jr Mcmahon JBJR (2005) Isolation and characterization of Griffithsin, a novel HIV-inactivating protein, from the red alga Griffithsia sp. J Biol Chem 280:9345-9353

6. Ziolkowska N, O'Keefe B, Mori T, Zhu C, Giomarelli B, Vojdani F, Palmer K, Mcmahon JA (2006) Domain-swapped structure of the potent antiviral protein Griffithsin and its mode of carbohydrate binding. Structure 14:1127

7. Lusvarghi S, Bewley CA (2016) Griffithsin: an antiviral lectin with outstanding therapeutic potential. Viruses 8:296

8. Xue J (2014) Investigation of the mechanism of Griffithsin (GRFT): a potent HIV entry inhibitor. Dissertations \& Theses-Gradworks

9. Millet JK, Séron K, Labitt RN, Danneels A, Palmer KE, Whittaker GR, Dubuisson J, Belouzard S (2016) Middle East respiratory syndrome coronavirus infection is inhibited by Griffithsin. Antivir Res 133:1-8

10. O'Keefe BR, Giomarelli B, Barnard DL, Shenoy SR, Chan PKS, Mcmahon JB, Palmer KE, Barnett BW, Meyerholz DK, Wohlfordlenane CL (2010) Broad-spectrum in vitro activity and in vivo efficacy of the antiviral protein Griffithsin against emerging viruses of the family Coronaviridae. J Virol 84:2511-2521

11. Meuleman P, Albecka A, Belouzard S, Vercauteren K, Verhoye L, Wychowski C, Lerouxroels G, Palmer KE, Dubuisson J (2011) Griffithsin has antiviral activity against hepatitis $\mathrm{C}$ virus. Antimicrob Agents Chemother 55:5159-5167

12. Takebe Y, Saucedo CJ, Lund G, Uenishi R, Hase S, Tsuchiura T, Kneteman N, Ramessar K, Tyrrell DL, Shirakura M (2013) Antiviral lectins from red and blue-green algae show potent in vitro and in vivo activity against hepatitis C virus. PLoS One 8:e64449 
13. Levendosky K, Mizenina O, Martinelli E, Jeanpierre N, Kizima L, Rodriguez A, Kleinbeck K, Bonnaire T, Robbiani M, Zydowsky TM (2015) Griffithsin and carrageenan combination to target herpes simplex virus 2 and human papillomavirus. Antimicrob Agents Chemother 59:7290-7298

14. Ishag HZ, Li C, Wang F, Mao X (2016) Griffithsin binds to the glycosylated proteins ( $\mathrm{E}$ and prM) of Japanese encephalitis virus and inhibit its infection. Virus Res 215:50-54

15. Ishag HZA, Li C, Huang L, Sun MX, Wang F, Ni B, Malik T, Chen PY, Mao X (2013) Griffithsin inhibits Japanese encephalitis virus infection in vitro and in vivo. Arch Virol 158:349-358

16. Fuqua JL, Wanga V, Palmer KE (2015) Improving the large scale purification of the HIV microbicide, Griffithsin. BMC Biotechnol $15: 12$

17. Moncla BJ, Pryke K, Rohan LC, Graebing PW (2011) Degradation of naturally occurring and engineered antimicrobial peptides by proteases. Adv Biosci Biotechnol 2:404-408

18. Kouokam JC, Lasnik AB, Palmer KE (2016) Studies in a murine model confirm the safety of Griffithsin and advocate its further development as a microbicide targeting HIV-1 and other enveloped viruses. Viruses 8:311

19. Kouokam JC, Huskens D, Schols D, Johannemann A, Riedell SK, Walter W, Walker JM, Matoba N, O'Keefe BR, Palmer KE (2011) Investigation of Griffithsin's interactions with human cells confirms its outstanding safety and efficacy profile as a microbicide candidate. PLoS One 6:e22635

20. Li L, Zheng Q, Zhang Y, Li P, Fu Y, Hou J, Xiao X (2016) Antiviral activity of recombinant porcine surfactant protein A against porcine reproductive and respiratory syndrome virus in vitro. Arch Virol 161:1883-1890

21. Urtasun N, Baieli MF, Cascone O, Wolman FJ, Miranda MV (2015) High-level expression and purification of recombinant wheat germ agglutinin in Rachiplusia nu larvae. Process Biochem 50:40-47

22. Woodrum BW, Maxwell J, Allen DM, Wilson J, Krumpe LR, Bobkov AA, Hill RB, Kibler KV, O'Keefe BR, Ghirlanda G (2016) A designed, "Nested" dimer of cyanovirin-N increases antiviral activity. Viruses 8:158

23. Li J, Tao S, Orlando R, Murtaugh MP (2015) N-glycosylation profiling of porcine reproductive and respiratory syndrome virus envelope glycoprotein 5. Virology 478:86-98
24. Li J, Murtaugh MP (2015) Functional analysis of porcine reproductive and respiratory syndrome virus $\mathrm{N}$-glycans in infection of permissive cells. Virology 477:82-88

25. Micewicz ED, Cole AL, Jung CL, Luong H, Phillips ML, Pratikhya P, Sharma S, Waring AJ, Cole AM, Ruchala P (2010) Grifonin-1: a small HIV-1 entry inhibitor derived from the algal lectin. Griffithsin. Plos One 5:e14360

26. Duan E, Wang D, Fang L, Ma J, Luo J, Chen H, Li K, Xiao S (2015) Suppression of porcine reproductive and respiratory syndrome virus proliferation by glycyrrhizin. Antivir Res 120:122-125

27. Li E, Sun N, Zhao JX, Sun YG, Huang JG, Lei HM, Guo JH, $\mathrm{Hu}$ YL, Wang WK, Li HQ (2015) In vitro evaluation of antiviral activity of tea seed saponins against porcine reproductive and respiratory syndrome virus. Antivir Ther 20:743

28. Feng J, Bai X, Cui T, Han Z, Yao C, Xie J, Shi Q, Wang H, Zhang $G$ (2016) In vitro antiviral activity of germacrone against porcine reproductive and respiratory syndrome virus. Curr Microbiol 73:1-7

29. Evans AB, Dong P, Loyd H, Zhang J, Kraus GA, Carpenter S (2017) Identification and characterization of small molecule inhibitors of porcine reproductive and respiratory syndrome virus. Antivir Res 146:28-35

30. Yang Q, Gao L, Si J, Sun Y, Liu J, Cao L, W-h Feng (2013) Inhibition of porcine reproductive and respiratory syndrome virus replication by flavaspidic acid AB. Antivir Res 97:66-73

31. Keirstead ND, Lee C, Yoo D, Brooks AS, Hayes MA (2008) Porcine plasma ficolin binds and reduces infectivity of porcine reproductive and respiratory syndrome virus (PRRSV) in vitro. Antivir Res 77:28-38

32. Balzarini J (2006) Large-molecular-weight carbohydrate-binding agents as HIV entry inhibitors targeting glycoprotein gp120. Curr Opin HIV AIDS 1:355-360

33. Nixon B, Stefanidou M, Mesquita PM, Fakioglu E, Segarra T, Rohan L, Halford W, Palmer KE, Herold BC (2013) Griffithsin protects mice from genital herpes by preventing cell-to-cell spread. J Virol 87:6257-6269 